\title{
Cricopharyngeal peroral endoscopic myotomy for achalasia of the cricopharynx: "to do or not to do"
}

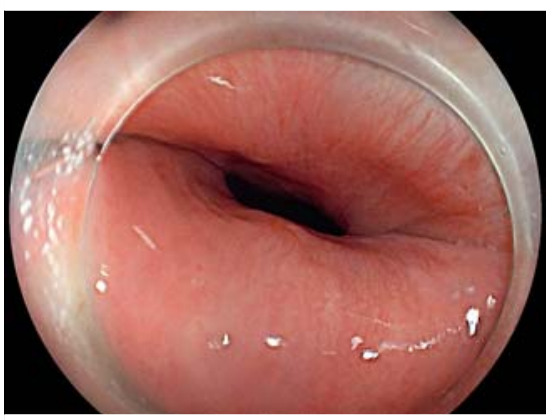

- Fig. 1 Cricopharyngeal bar.

Cricopharyngeal achalasia is a rarely reported [1] entity traditionally treated by surgery [2]. The video shows two cases referred to our unit for cricopharyngeal peroral endoscopic myotomy (CPOEM).

The first case was a 40-year-old woman with a 2-year history of cervical dysphagia requiring enteral feeding. Previous gastroscopy, barium transit, and high resolution manometry (HRM) were compatible with cricopharyngeal achalasia. A neck ultrasound and computed tomography (CT) without intravenous contrast supported the diagnosis. During the endoscopy for C-POEM, an upper compression that flattened with the endoscope and presented a beat was observed. An urgent angio-CT diagnosed the patient with lusoria dysphagia. Therefore, no endoscopic treatment was performed and the patient was referred for vascular bypass surgery.

The second case was an 83-year-old man with upper dysphagia and laryngeal microaspirations. Barium transit showed an upper posterior imprint ( $\mathbf{V i d e o} \mathbf{1}$ ) and HRM was compatible with cricopharyngeal achalasia. At gastroscopy, it was not possible to pass the upper esophageal sphincter. A CT scan with contrast ruled out extrinsic compressions. The patient was reluctant to undergo therapeutic maneuvers and accepted a treatment with botulinum toxin, which subsequently worsened the symptoms. Videoradiology and a new manometry reaffirmed the diagnosis of cricopharyngeal achala-
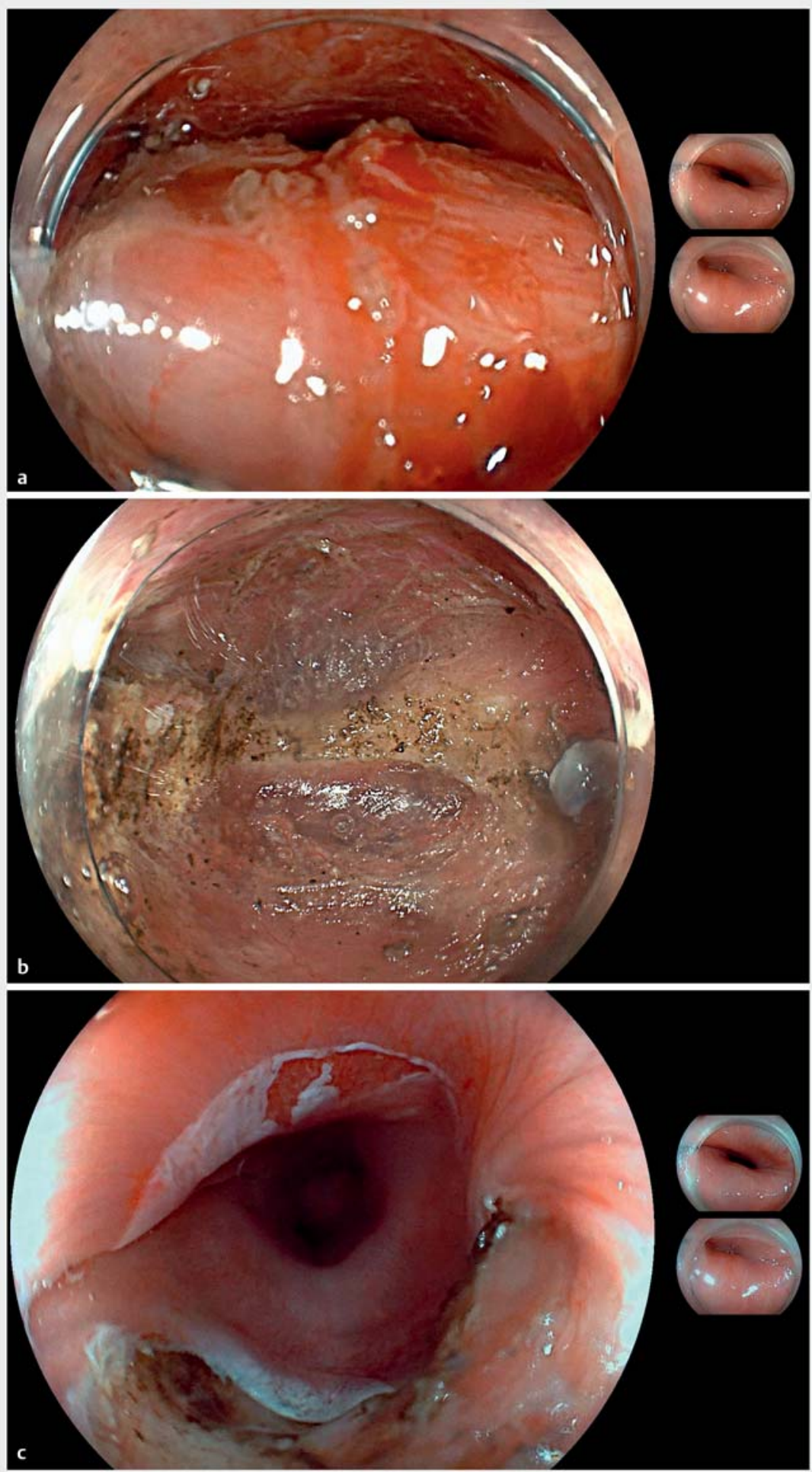

- Fig. 2 Myotomy of the cricopharyngeal bar. a Exposed cricopharyngeal bar. b Complete cricopharyngeal bar myotomy. $\mathbf{c}$ Disappearance of the bar from the esophageal lumen after myotomy. 


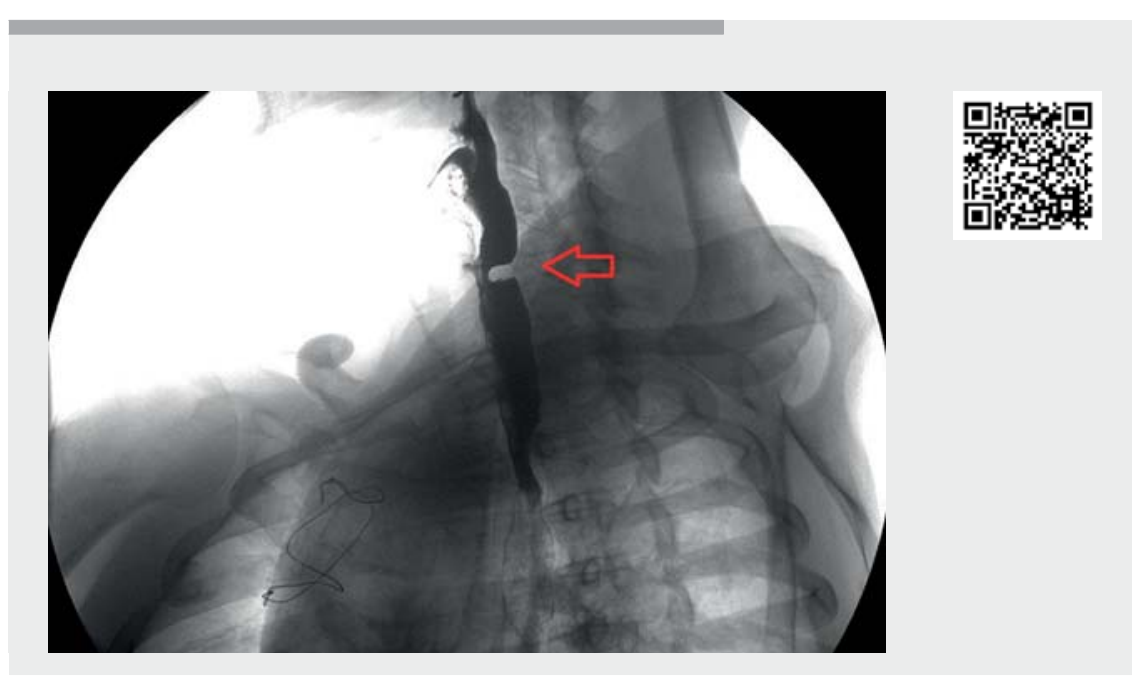

Video 1 Cricopharyngeal peroral endoscopic myotomy (C-POEM) is a feasible treatment for cricopharyngeal achalasia without associated Zenker's diverticulum, although it requires an adequate diagnosis and exclusion of other causes of upper dysphagia.

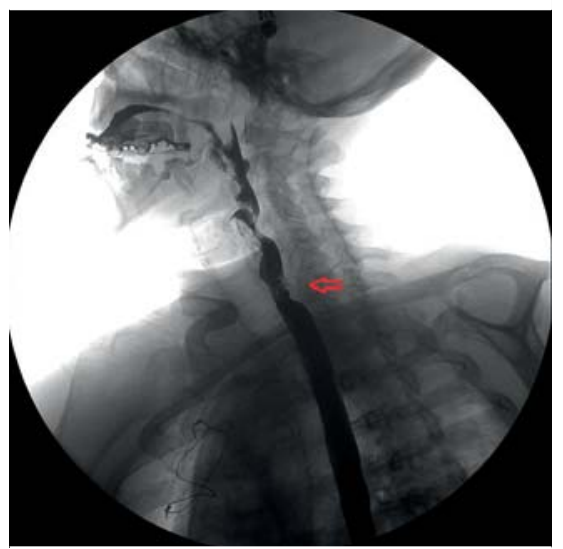

Fig. 3 Normal barium transit the day after myotomy.

sia. Finally, the patient agreed to undergo C-POEM.

After initial tunneling without cap owing to the limited space, a myotomy of the cricopharyngeal bar ( $>$ Fig.1) was performed with subsequent closure of the mucosotomy with clips ( $\mathbf{F i g . 2}$ ). The patient experienced immediate symptomatic improvement that was confirmed by barium transit ( $\$$ Fig. 3 ), and remained asymptomatic after 5 months.

Cricopharyngeal achalasia without Zenker's diverticulum requires careful diagnosis to exclude other pathologies $[3,4]$. The limited space due to the cricopharyngeal bar can make endoscopic diagnosis and treatment difficult. Working

Endoscopy_UCTN_Code_TTT_1AO_2AN

\section{Competing interests}

The authors declare that they have no conflict of interest.

\section{The authors}

\section{Eduardo Albéniz ${ }^{1} 2$ @ Fermín Estremera-}

Arevalo ${ }^{1}$, Pedro J. Rosón ${ }^{3}$, Francisco

Fernandez $\mathrm{Cano}^{4}$, María L. Heredia ${ }^{5}$, Sauid

Ishaq ${ }^{6,7}{ }^{\odot}$, Juan J. Vila ${ }^{1} \odot$

1 Endoscopy Unit, Gastroenterology Department, Complejo Hospitalario de Navarra, Pamplona, Spain

2 Navarrabiomed Biomedical Research Center, Public University of Navarre, Navarre Institute for Health Research, Pamplona, Spain

3 Gastroenterology Endoscopy Unit, Hospital Quirónsalud Málaga, Málaga, Spain

4 Digestive System and Endoscopy Unit, Hospital Quirónsalud Málaga, Málaga, Spain

5 Gastroenterology Department, Mateu Orfila General Hospital, Mahon, Spain

6 Health and Science, Birmingham City University, Birmingham, United Kingdom

7 University of Birmingham, Russells Hall Hospital, Birmingham, United Kingdom

\section{Eduardo Albéniz, MD, PhD}

Endoscopy Unit, Gastroenterology

Department, Complejo Hospitalario de

Navarra, Irunlarrea 3, 31008, Navarra, Spain

edualbeniz@hotmail.com

\section{References}

[1] Chen JM, Chen YJ, Ni J et al. Ultrasound, electromyography, and balloon guidance for injecting botulinum toxin for cricopharyngeal achalasia: a case report. Medicine (Baltimore) 2021; 100: e24909

[2] Jayawardena ADL, Miller LE, Hirner L et al. Modified external approach to the pediatric cricopharyngeal myotomy: a case series. Int J Pediatr Otorhinolaryngol 2020; 132: 109899

[3] Elmunzer B], Moran RA. Peroral endoscopic myotomy for cricopharyngeal bar. VideoGIE 2020; 5: 378-379

[4] Al Ghamdi SS, Farha J, Runge TM et al. No pouch, no problem: successful endoscopic division of a symptomatic cricopharyngeal bar using a modified peroral endoscopic myotomy technique for Zenker's diverticulum. VideoGIE 2020; 5: 281-282

Bibliography

Endoscopy 2022; 54: E382-E383

DOI 10.1055/a-1544-7677

ISSN 0013-726X

published online 9.8.2021

(c) 2021. Thieme. All rights reserved. Georg Thieme Verlag KG, Rüdigerstraße 14, 70469 Stuttgart, Germany

\section{ENDOSCOPY E-VIDEOS}

https://eref.thieme.de/e-videos

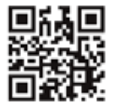

Endoscopy E-Videos is an open access online section, reporting on interesting cases and new techniques in gastroenterological endoscopy. All papers include a high quality video and all contributions are freely accessible online. Processing charges apply (currently EUR 375), discounts and wavers acc. to HINARI are available.

This section has its own submission website at https://mc.manuscriptcentral.com/e-videos 